\title{
Influence of Tooth Profile Modification on Spur Gear Dynamic Tooth Strain
}

Fred B. Oswald and Dennis P. Townsend

Lewis Research Center

Cleveland, Ohio

Prepared for the

31st Joint Propulsion Conference and Exhibit cosponsored by AIAA, ASME, SAE, and ASEE

San Diego, California, July 10-12, 1995

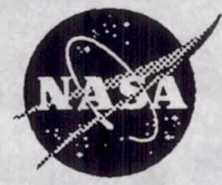

National Aeronautics and

Space Administration

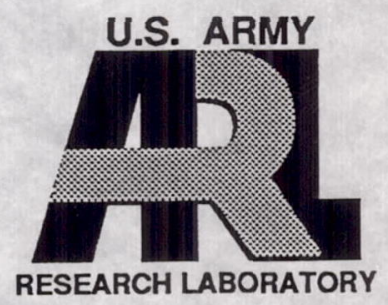




\title{
Influence of Tooth Profile Modification on Spur Gear Dynamic Tooth Strain
}

\author{
Fred B. Oswald and Dennis P. Townsend \\ NASA Lewis Research Center, Cleveland, Ohio 44135
}

\begin{abstract}
This paper presents results of dynamic strain gage measurements performed on the NASA gear-noise rig. The experiments were part of a joint research program between NASA and the U.S. Army Research Laboratory to advance the technology of rotorcraft transmissions. Tests were performed on six sets of low contact ratio spur gears with different tooth profile modifications. Results presented include static and dynamic measurements of gear tooth strain taken over a matrix of operating conditions. The results demonstrate that a well-designed tooth profile modification can significantly reduce dynamic loads in spur gears, especially for gears which operate at high speed and under high torque. The two parabolic modifications tested were not as effective as linear modifications, possibly because the modification zone was too long.
\end{abstract}

\section{INTRODUCTION}

A major source of helicopter cabin noise (which has been measured at over 100 decibels sound pressure level) is the gearbox. Reduction of this noise is a NASA and US Army goal.

Noise excitation in a transmission is caused by the load fluctuation as gear teeth enter and leave mesh. The cyclic variation in the numbers of teeth carrying the load causes a periodic change in the tooth stiffness and affects the relative position of the teeth. Any deviation in the angular position of the driven gear from its ideal position is called the transmission error. Transmission error arises from manufacturing and mounting errors and from tooth deflection under load.

High-quality gear designs often include modified tooth profiles (tip relief) to minimize transmission error. Dudley's Gear Handbook (Townsend, 1991) provides formulas for "first approximations" of tip relief based on the load and face width. Previous studies of spur gear profile modification include Tavakoli and Houser (1984), Munro, et al. (1990), Munro (1989), and Lin et al. (1989). Dynamic strain gage testing was reported in Rebbechi, et al. (1991) and Oswald, et al. (1991).

The goal for the research reported in this paper was to examine the influence of tooth profile modification on dynamic tooth strain by means of controlled tests and to provide a database for further research. Data presented here include involute (tooth profile) charts for the test gears and time domain plots of static and dynamic gear tooth bending strain.

\section{APPARATUS}

Tests were performed on the NASA gear noise rig (figure 1). The rig features a single-mesh gearbox powered by a $150 \mathrm{~kW}(200 \mathrm{hp})$ variable speed electric motor. An eddy-current dynamometer loads the output shaft. The gearbox can operate at speeds up to 6000 $\mathrm{rpm}$. The rig was built to carry out fundamental studies of gear noise and the dynamic behavior of gear systems. It is designed to allow testing of various configurations of gears, bearings, dampers and supports. The gearbox is extensively instrumented for strain, noise and vibration measurements.

A poly-V belt drive was used as a speed increaser between the motor and input shaft. A soft coupling on the input shaft reduces input torque fluctuations caused by non-uniformity of the belt splice.

The gearbox oil inlet temperature was maintained at 70 $+/-2^{\circ}$ Celsius for these tests. At the mean temperature of $70^{\circ}$, the viscosity of the synthetic turbine engine oil (MIL-L-23699B) used in the tests is 9.5 centistoke.

\section{Instrumentation}

General-purpose, constantan foil, resistance strain gages with gage length $0.38 \mathrm{~mm}(0.015 \mathrm{in})$ were installed in the tooth-root fillets on both the loaded 

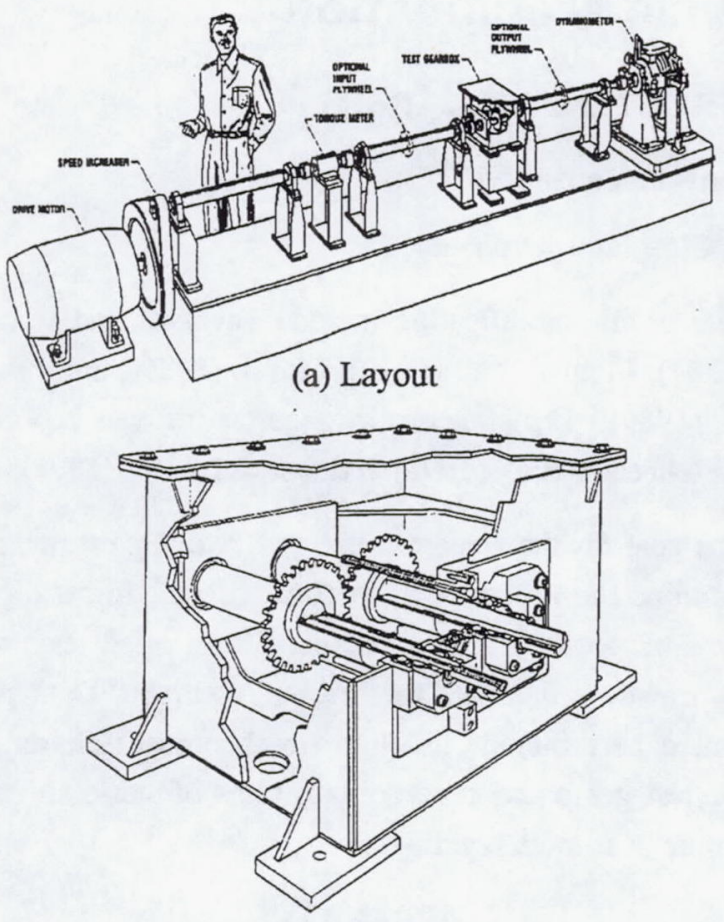

(b) Detail of gearbox

Figure 1.--NASA gear noise rig

(tensile) and unloaded (compression) side of two adjacent teeth on the output (driven) gear (Fig. 2). To measure maximum tooth bending stress, the gages were placed at the $30^{\circ}$ tangency location (Cornell, 1980). Two methods of signal conditioning were used on strain gage signals: For static measurement, a strain gage (Wheatstone) bridge was used. For dynamic measurements, the strain gages were connected via a slip-ring assembly to constant-current strain gage amplifiers.

An eight channel, 12-bit digital data acquisition system was used to record the dynamic strain data. The sample rate was varied from $6.6-50 \mathrm{kHz}$ per channel to provide 500 samples per revolution for each channel. An optical encoder on the input gear shaft produced an accurate once-per-rev pulse. The encoder was adjusted so the leading edge of its pulse occurred at a known roll angle of the gear. This allowed us to determine the roll angle at any point in the data record.

Test Gears The test gears were identical spur gears (at 1:1 ratio) machined to master gear (AGMA Class 15)

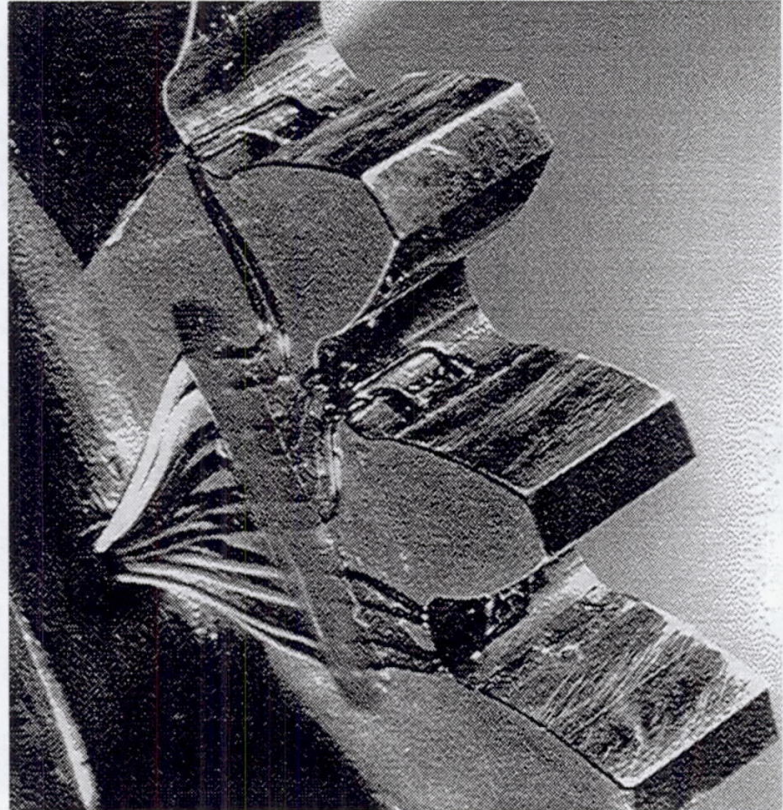

Figure 2.--Strain gage installation on test gear

accuracy. Test gear parameters are shown in Table 1. Profile modifications were chosen to compensate for tooth deflection under load. No additional allowance was made for manufacturing errors since these errors were not more than one-tenth of the computed deflection at the nominal load of $71.8 \mathrm{~N}-\mathrm{m}$ (635 lb-in).

TABLE 1, Test Gear Parameters

Gear Type

Standard, full-depth tooth

No. teeth

28

Module, $\mathrm{mm}$ (diametral pitch, in ${ }^{-1}$ )

$3.175(8)$

Face width, mm (in)

$6.35(0.25)$

Pressure Angle, deg

Theoretical contact ratio

1.64

Tooth root radius, $\mathrm{mm}$ (in)

$1.35(0.053)$

Max. tooth spacing error, $m$ (in)

$1.8(0.00007)$

Max. profile error, $m$ (in)

$1.3(0.00005$

Six different gear profiles (Fig. 3) were tested. These include an unmodified profile, three combinations of linear profile modification (tip relief) and two different forms of parabolic modification. Linear modification is defined by two parameters: (1) the amount of modification at the tip and (2) the roll angle at the start of modification. For parabolic modification, a third parameter is needed. We identified two forms of this third parameter: In type-1 parabolic relief (see Fig. 

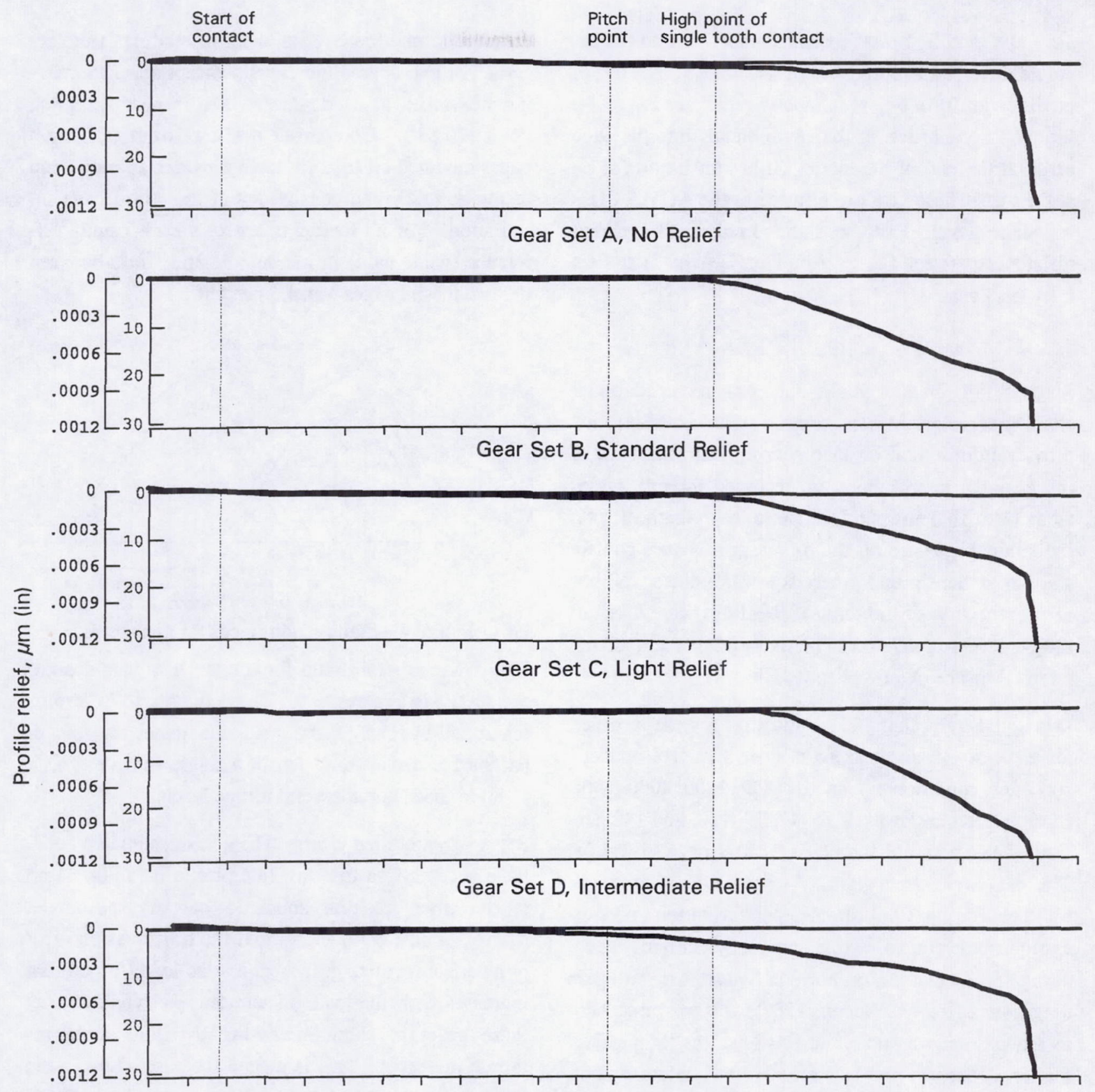

Gear Set E, Parabolic Type-1 Relief

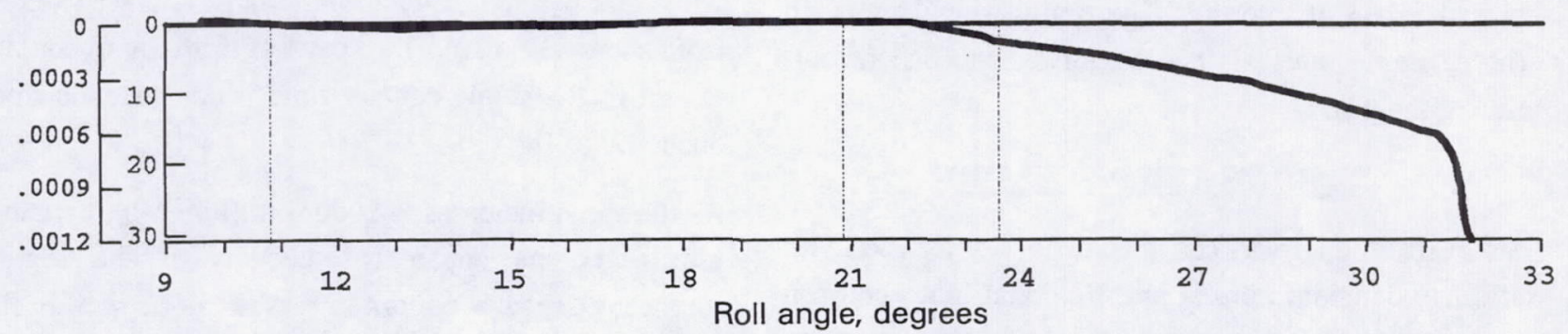

Gear Set F, Parabolic Type-2 Relief

Figure 3.--Profile charts for the six sets of test gears 
3-E), the modified profile blends smoothly into the involute trace. (It is tangent to the involute at the start of modification.) In type-2 parabolic relief (see Fig. 3-F), the modified portion of the curve blends into the edge break at the end of the tooth. (It has an infinite slope at the tip.) These gears were made to the AGMA Class 15 quality level. Even so, there is not much apparent difference between the traces for set $E$ (type-1) and set F (type-2) gears.

\section{TEST PROCEDURE}

Static Strain Data: Strain data was recorded under static (non-rotating) conditions. Static measurements provide information on load sharing characteristics of the gear pairs. Strains were recorded for roll angles from 32 to 10 degrees roll angle for each tooth. (Note: the strain gages are on the driven gear, hence contact starts near the tip and proceeds towards lower roll angles at the root of the tooth.) Readings were taken at torque levels of $57,85,113$ and 142 percent of the nominal torque of $71.8 \mathrm{~N}-\mathrm{m}$ (635 lb-in)).

Dynamic Strain Data: Dynamic strains were recorded for each of the six gear pairs over a matrix of loadspeed test conditions: 4 speeds $(800,2000,4000,6000$ rpm) and torque levels of $16,47,79,110$, and 142 percent of the nominal torque of $71.8 \mathrm{~N}-\mathrm{m}(635 \mathrm{lb}-\mathrm{in})$ ). The data were then digitally resampled, using linear interpolation, at 1000 samples per revolution and synchronously averaged. Time domain synchronous averaging is a technique now in wide use in gear diagnostics (see McFadden, 1987), and was used here to reduce random "noise" effects (such as torque fluctuation caused by the belt drive). Its implementation requires at least two channels of data - a timing signal plus the data of interest. The timing signal provided the resample intervals needed for exactly one revolution of the gear.

\section{RESULTS AND DISCUSSION}

Static strain data was collected primarily for use in an effort to compute normal and frictional loads between gear teeth (see Rebbechi, et al., 1991). Fig. 4 shows static strain data from two consecutive teeth on gear set B (standard "long relief" profiles) taken at four different torque levels. Static strain readings were recorded at two degree increments except an extra reading was taken at 21 degrees which is near the pitch point $\left(20.85^{\circ}\right)$. Comparing readings from the strain gages mounted on adjacent teeth provides an indication of the accuracy and consistency of the strain gage installation. For all the gears tested, the maximum difference (worst case) in measured static strain between the two tensile gages was 4.6 percent.

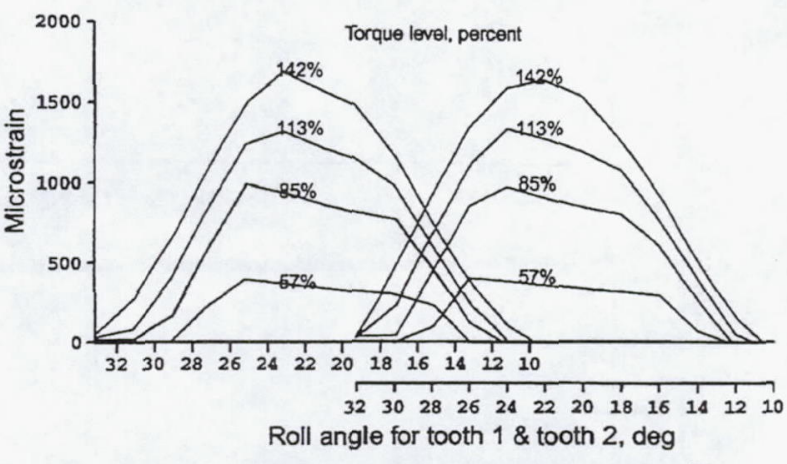

Figure 4.--Static strain traces for gear set $\mathrm{B}$

The dynamic strain data for the six test gear designs are shown in Figures 5-10. These figures show strains measured by one of the load-side gages as sets of parametric curves, each set for a single gear design, at a single speed but at several torque levels.

Set A - Unmodified Gears: The gears designated Set A have essentially a true involute profile (see Fig. 3) up to the edge break at about 31 degrees roll angle. Munro, et al. (1990) shows that the transmission error of a perfect involute gear is zero at no load (torque) but increases with the load. Therefore, we would expect these gears to show increasing dynamic action as torque increases. This is indeed the case. Low-speed measurements (Fig. 5-a) show very smooth operation with little dynamic excitation. Tooth contact extends from about $32^{\circ}$ to $10^{\circ}$. Two pairs of teeth are in contact except in the single contact zone which extends from about $22^{\circ}$ to $18^{\circ}$

As the speed increases to $2000 \mathrm{rpm}$ (Fig. 5-b), dynamic effects become apparent, especially at the higher torques. A regular pattern of waves can be seen in the strain curves. At $2000 \mathrm{rpm}$, one tooth pitch period occupies about $13^{\circ}$ of roll angle $\left(360^{\circ}\right.$ divided by 28 teeth). In this span there are about four cycles of 
strain. This indicates that the dynamic loading frequency is four times the tooth mesh frequency. At $4000 \mathrm{rpm}$ (fig 5-c), the dynamic action is much stronger and there are two strain cycles per tooth pitch. At $6000 \mathrm{rpm}$, the dynamic effects are not as strong and there is no regular wave pattern.

Set B - Standard Relief: The strain data from set B gears is shown in Fig. 6. Because of dynamometer control problems at the time these data were taken, the highest torque (142 percent) curve is missing in Figs. 6-a and 6-d.

Set B gears have linear profile modification (Fig 3) extending from the high point of single tooth contact to the tip. Munro calls this "long relief". (In contrast, "Short" relief has a modification zone one-half as long.) The amount of relief at the tooth tip corresponds to the tooth deflection expected from a torque level of 115 percent of the nominal $71.8 \mathrm{~N}-\mathrm{m}$.

The low speed traces (Fig. 6-a) show that the single contact zone is longer than in the set A gears. The profile modification has apparently decreased the contact ratio. At higher speeds (Figs. 6-b to 6-d), there was smooth operation near the design torque but much rougher operation away from design torque, especially at high speed, low torque conditions. At $4000 \mathrm{rpm}$ and 16 percent torque, there are two strain "spikes" at the beginning and end of tooth contact and the strain is zero at the pitch point. This indicates that the teeth bounce out of contact. At $6000 \mathrm{rpm}$ and 16 percent torque, there is a single large strain spike. This indicates relatively high dynamic loading.

Set C - Light relief: The gears from set $\mathrm{C}$ are similar to set $\mathrm{B}$ except the amount of relief is much less, corresponding to the deflection for 70 percent torque As would be expected, these gears operate more smoothly at light torque but with increased dynamics at higher torques.

Set D - Intermediate relief: Set D gears have a shorter relief zone than sets B or C. Munro, et al. (1990) calls this "Intermediate relief" and recommends it for gears which operate under a range of loads. The amount of relief at the tooth tip corresponds to 135 percent torque. The results (Fig. 8) show very smooth operation at high torque, and light torque operation is comparable to set B. Since they show improvement at high torque and no worse operation at low torque (compared to set $\mathrm{B}$ ) intermediate relief is an improvement over long relief.

Set E - Parabolic Type-1: These gears are similar to set $C$ gears except the modification zone extends to the pitch point. (Munro calls this "extra long relief".) The modification at the tip corresponds to torque of 65 percent. These gears were difficult and expensive to manufacture. Their performance was disappointing. The dynamic strains were large at both high and low torques. Results may have been better if the relief zone were much shorter.

Set F - Parabolic Type-2: These gears are similar to set $E$ except the modification amount at the tip corresponds to the tooth deflection at 85 percent torque and the modification zone is slightly shorter. Like set $\mathrm{E}$, these are difficult and expensive to manufacture. The performance was similar to that of set $E$

\section{SUMMARY AND CONCLUSIONS}

Low contact ratio spur gears with various profile modifications were tested in the NASA gear noise rig. Dynamic tooth bending strains were recorded for each gear design at 36 operating conditions. The experimental results were compared to examine the influence of the tooth profile on the dynamic behavior of the gears under various operating conditions. The following conclusions were drawn from the data:

1. The proper type and amount of tooth profile modification can significantly reduce dynamic loads in spur gears, especially for gears which operate at high speed and under high torque.

2. The parabolic modification gears tested here seem not to offer any advantage. This may be because the modification zone is too long.

3. Profile modification increases dynamic loads in gears which operate significantly below their design torque, This is especially so for a long modification zone. 


\section{REFERENCES}

Cornell, R.W., 1980, "Compliance and Stress Sensitivity of Spur Gear Teeth," ASME Paper 80-C2/DET-24.

Lin, Hsiang Hsi, Oswald, Fred B., Townsend, Dennis P., 1989, "Dynamic Loading of Spur Gears With Linear or Parabolic Tooth Profile Modification", Proceedings of ASME 1992 Intl Power Trans \& Gearing Conf, Chicago, Sept, 1989 (Also NASA-TM-101444.)

McFadden, P. D., 1987, Examination of a Technique for the Early Detection of Failure in Gears by Signal Processing of the Time Domain Average of the Meshing Vibration. Mechanical Systems and Signal Processing, Vol. 1, No. 2, 1987, pp. 173-183.

Munro, R.G., Yildirim, N., Hall, D.M., 1990, "Optimum Profile Relief and Transmission Error in Spur Gears", Proceedings of the Institution of Mechanical Engineers, First International Conference on Gearbox Noise and Vibration, University of Cambridge, England.
Munro, R.G., 1989, "The D.C. Component of Gear Transmission Error", Proceedings of ASME 1989 Intl Power Trans \& Gearing Conf, Chicago, Apr, 1989.

Oswald, Fred B., Rebbechi, Brian; Zakrajsek, James J; Townsend, Dennis P, 1991, Comparison of Analysis and Experiment for Dynamics of Low Contact Ratio Spur Gears, NASA TM 103232, AVSCOM TR-90-C-017.

Rebbechi, B., Oswald, F. B., Townsend, D. P., 1991, "Dynamic Measurements of Gear Tooth Friction and Load," AGMA report 91-FTM-10. (Also NASA TM-103281.)

Tavakoli, M.S., Houser, D.P., 1984, "Optimum Profile Modifications for the Minimization of Static Transmission Errors of Spur Gears", Journal of Mechanisms, Transmissions, and Automation in Design, Vol. 108, No. 1, pp. 86-95, (ASME paper 84-DET-173.)

Townsend, Dennis P., editor, 1991, Dudley's Gear Handbook, 2nd Edition, McGraw-Hill, Inc. 


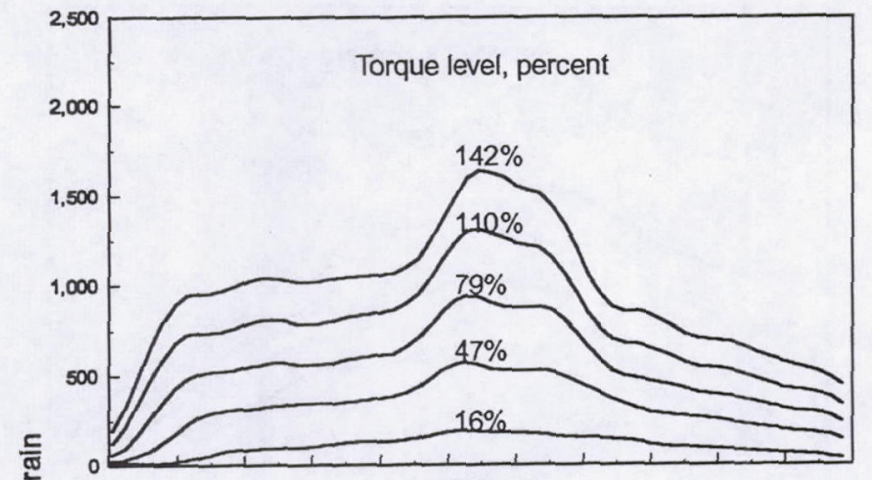

(a) $800 \mathrm{rpm}$

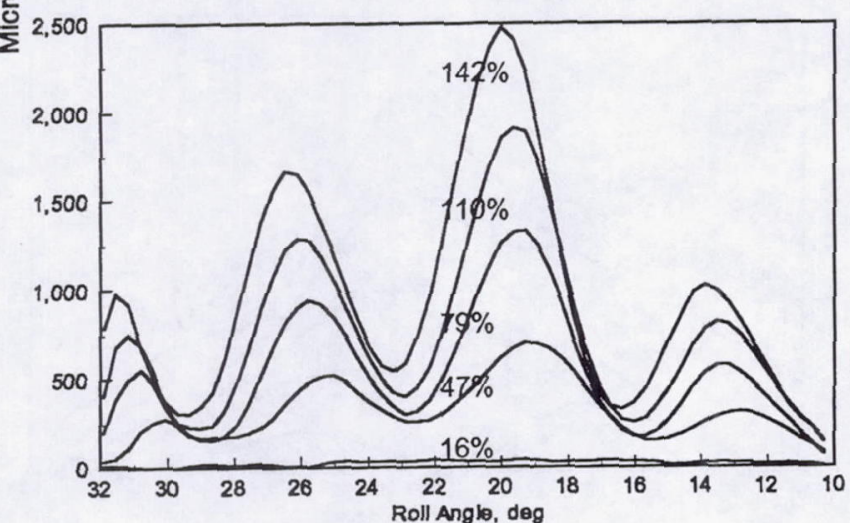

(c) $4000 \mathrm{rpm}$

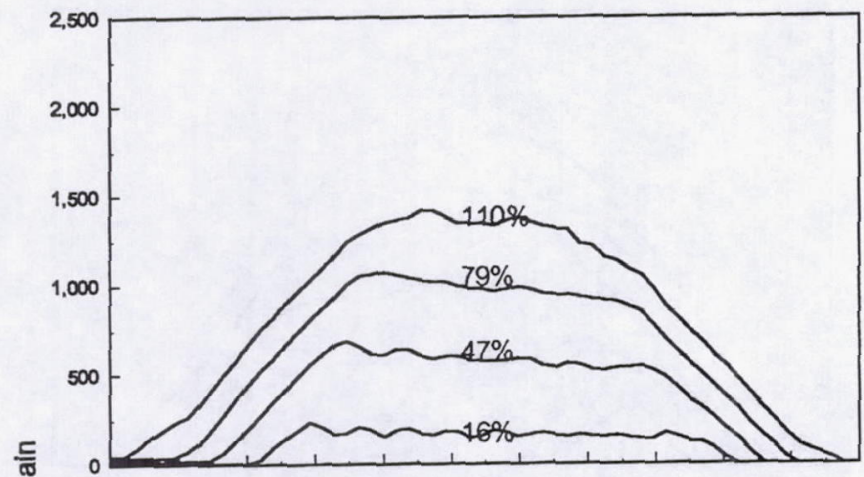

(a) $800 \mathrm{rpm}$

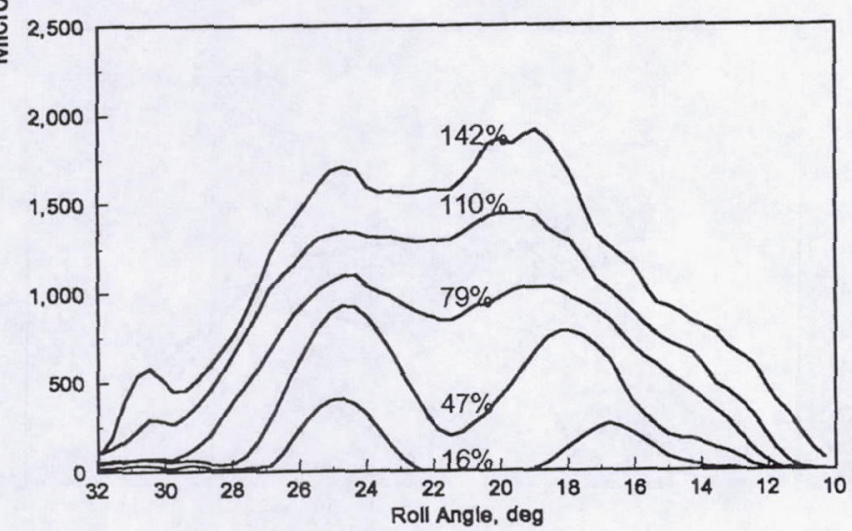

(c) $4000 \mathrm{rpm}$

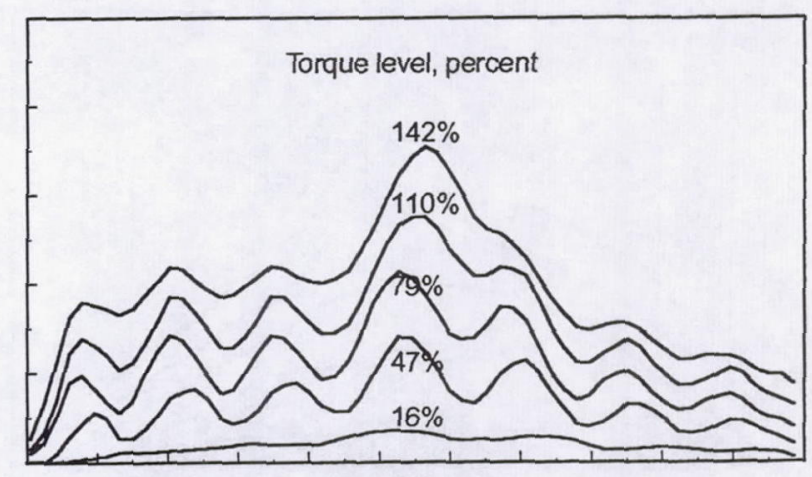

(b) $2000 \mathrm{rpm}$

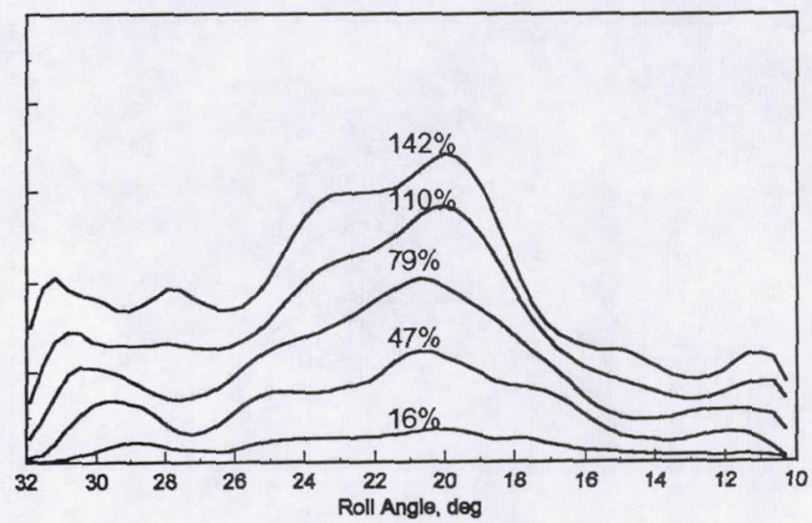

(d) $6000 \mathrm{rpm}$

Figure 5.--Gear set A, no relief

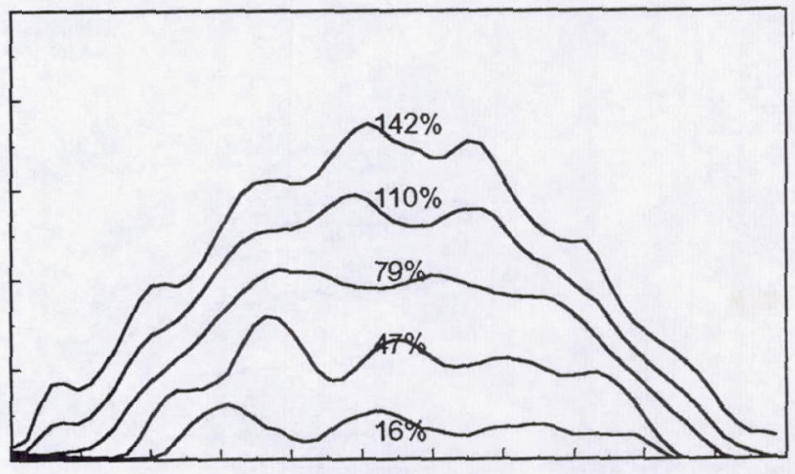

(b) $2000 \mathrm{rpm}$

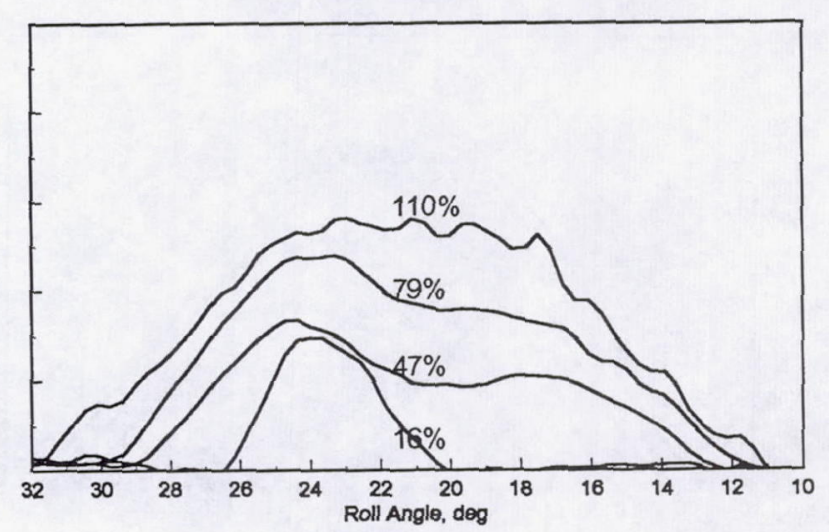

Figure 6.--Gear set B, standard relief

(d) $6000 \mathrm{rpm}$ 


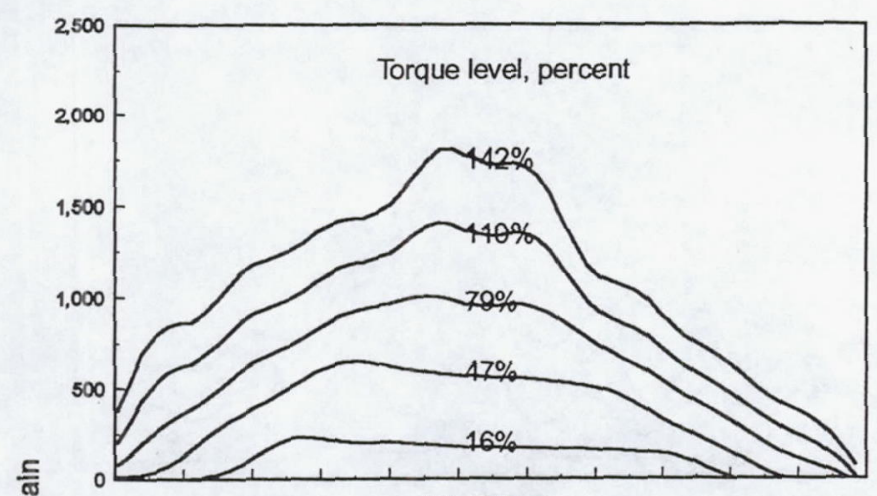

(a) $800 \mathrm{rpm}$

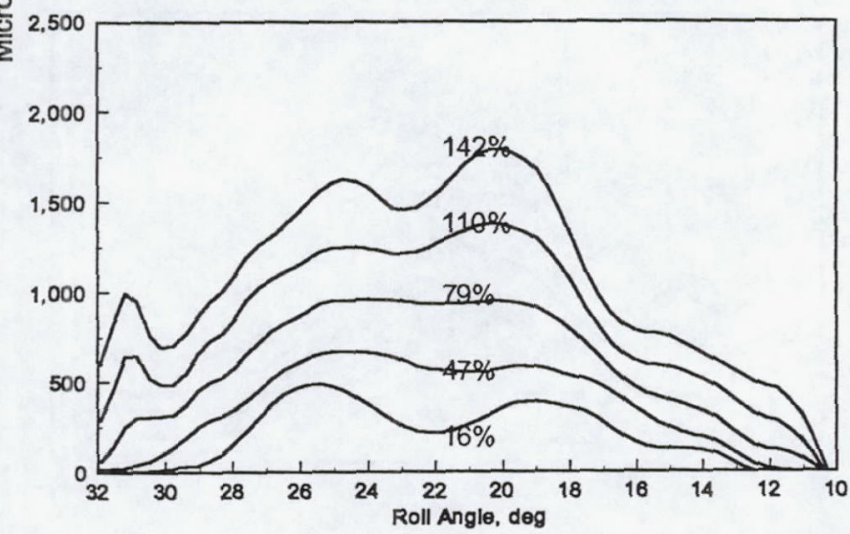

(c) $4000 \mathrm{rpm}$

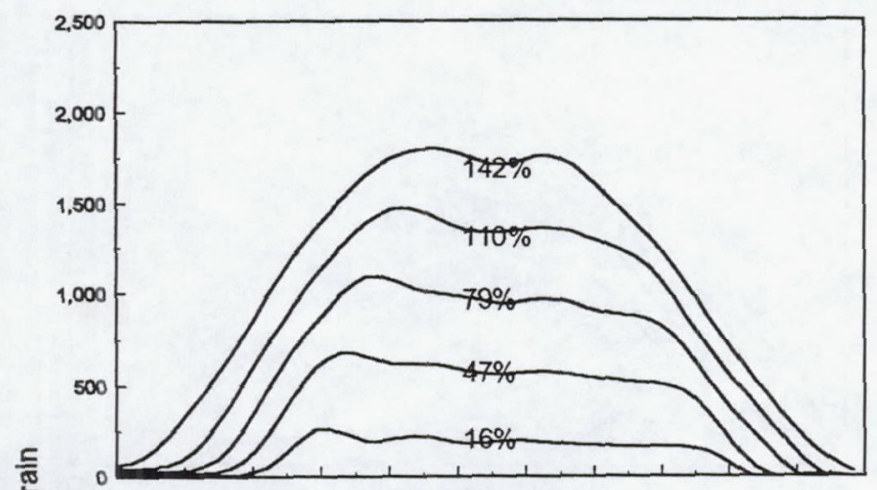

(a) $800 \mathrm{rpm}$

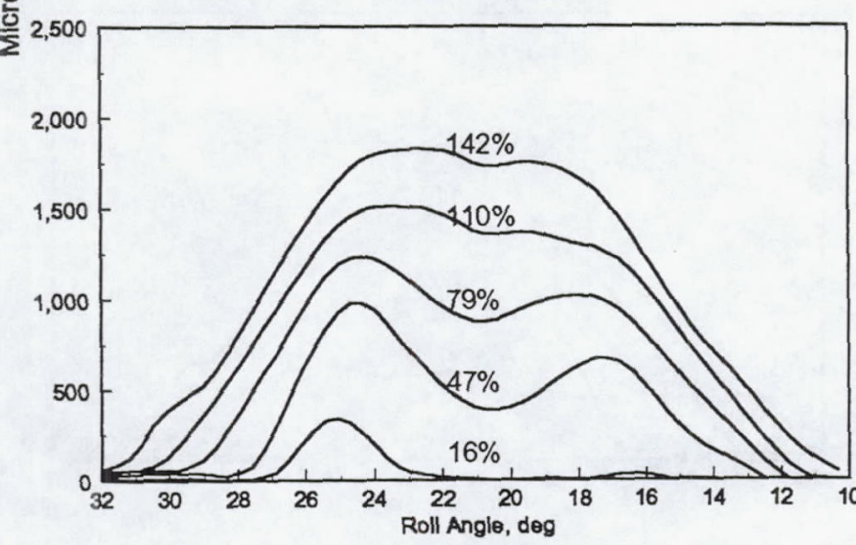

(c) $4000 \mathrm{rpm}$

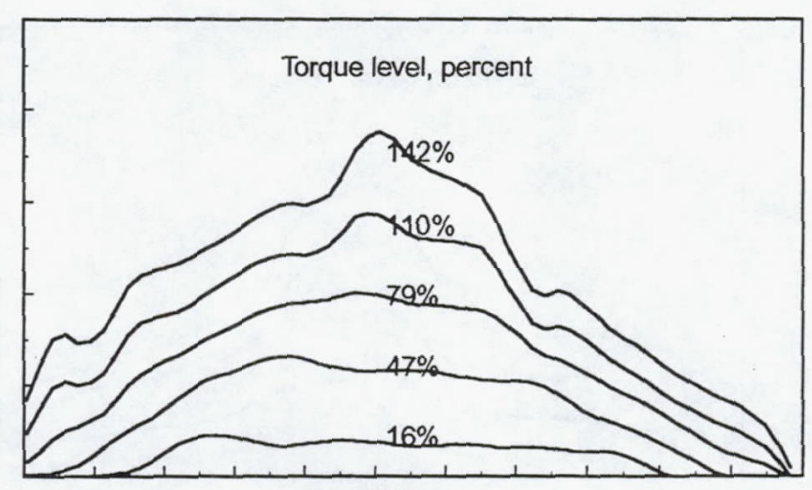

(b) $2000 \mathrm{rpm}$

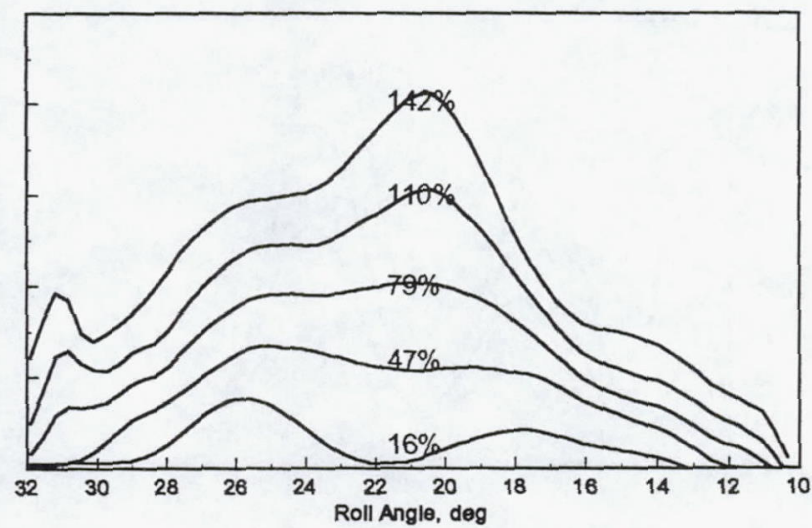

(d) $6000 \mathrm{rpm}$

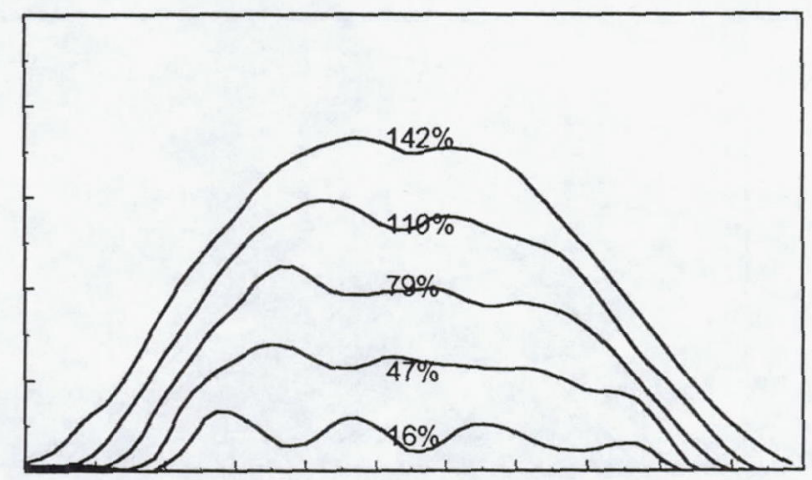

(b) $2000 \mathrm{rpm}$

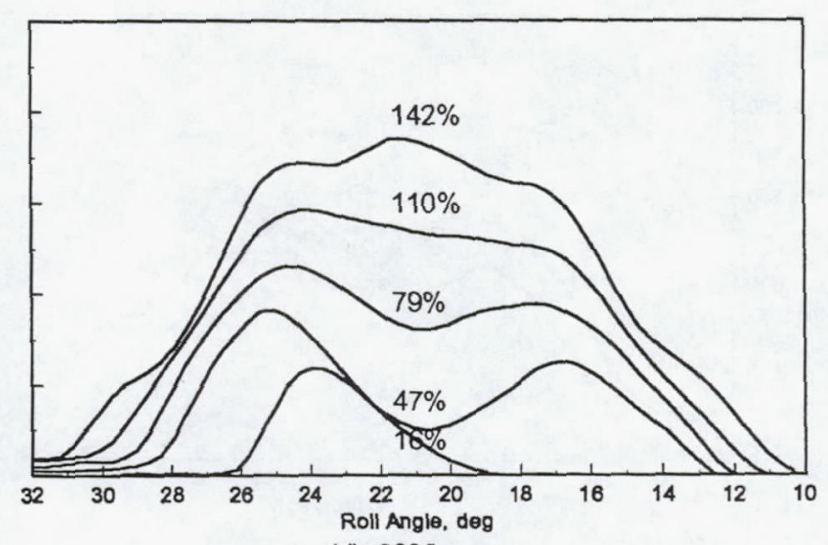

(d) $6000 \mathrm{rpm}$

Figure 8.--Gear set D, intermediate relief 


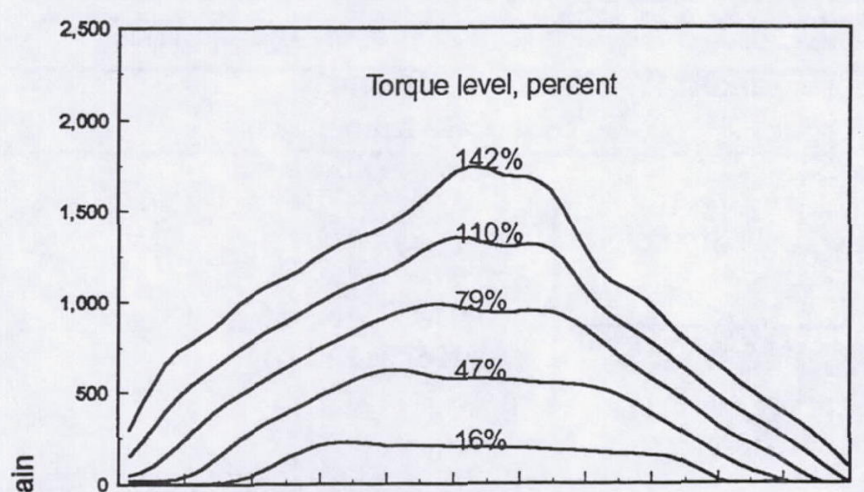

(a) $800 \mathrm{rpm}$

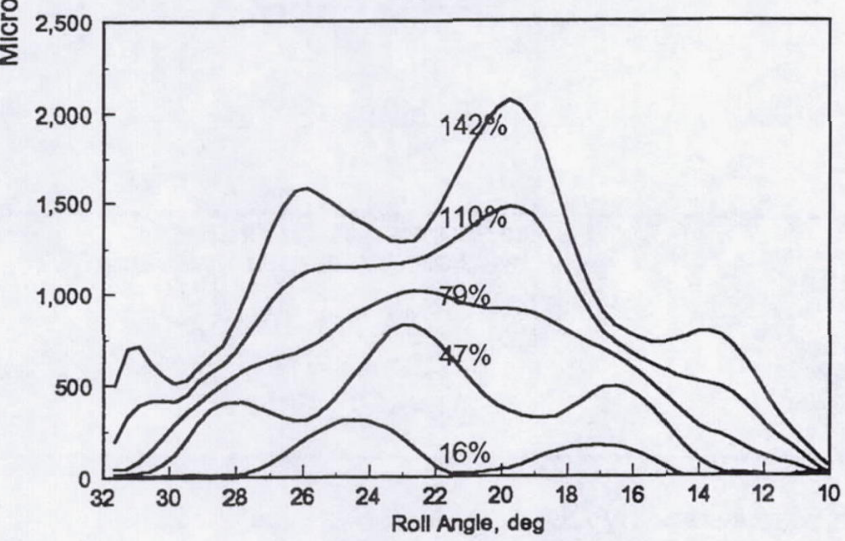

(c) $4000 \mathrm{rpm}$

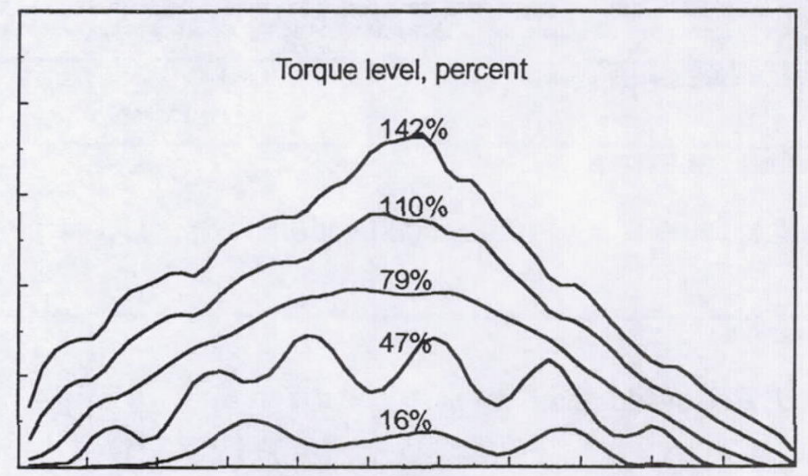

(b) $2000 \mathrm{rpm}$

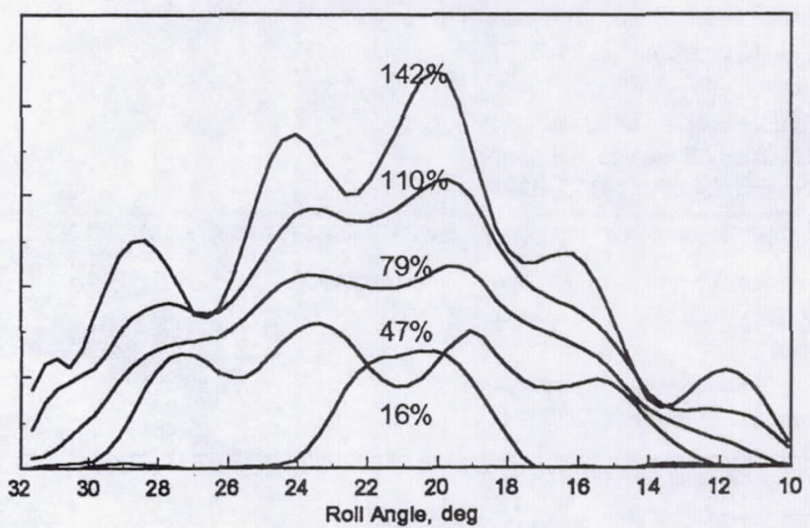

(d) $6000 \mathrm{rpm}$

Figure 9.-- Gear set E, parabolic type-1 relief

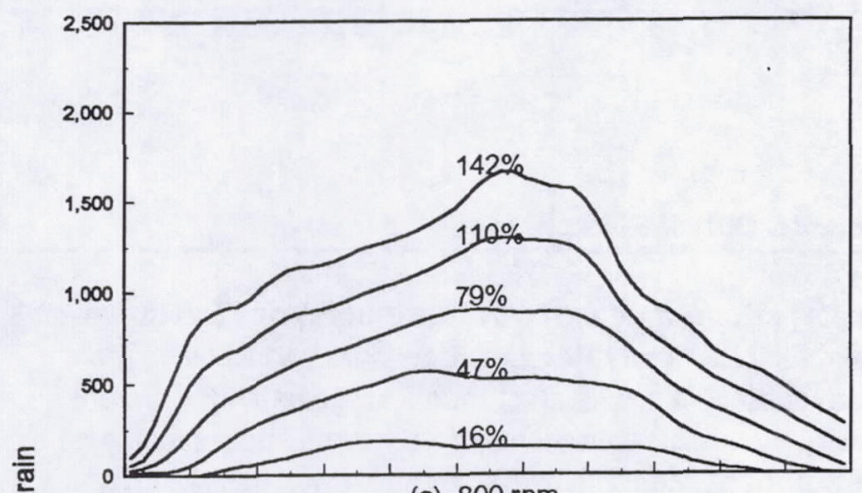

(a) $800 \mathrm{rpm}$

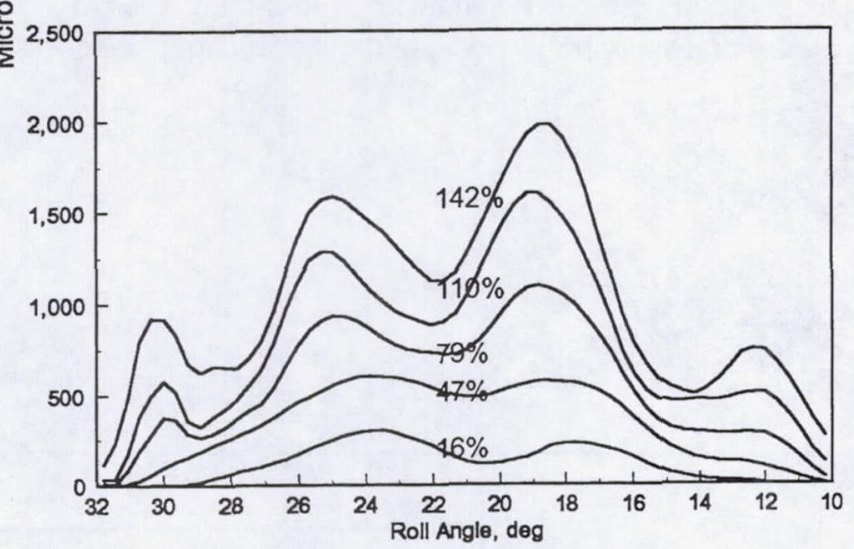

(C) $4000 \mathrm{rpm}$

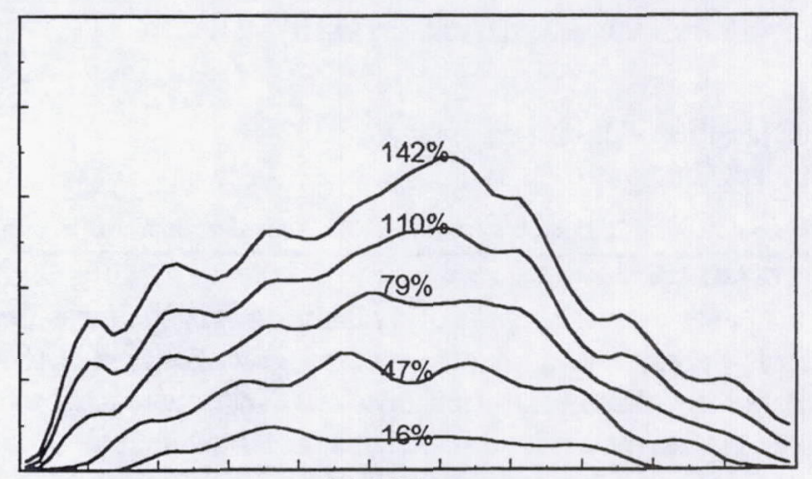

(b) $2000 \mathrm{rpm}$

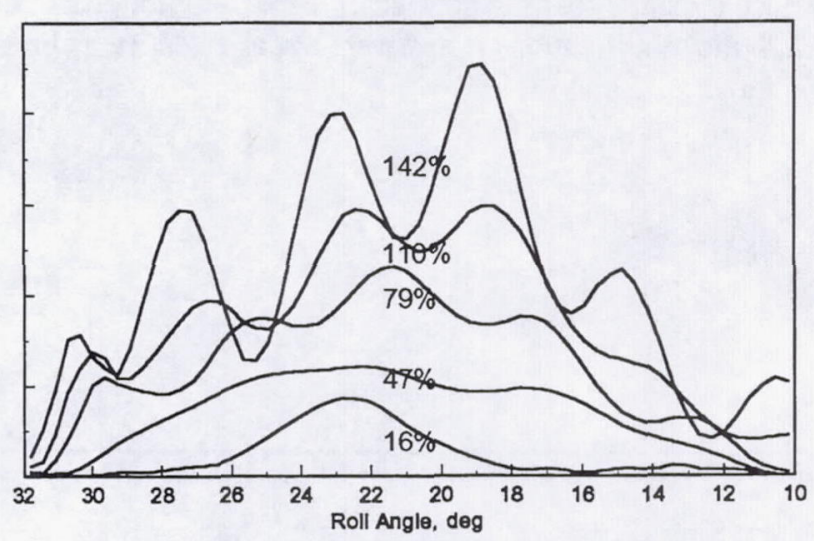

(d) $6000 \mathrm{rpm}$

Figure 10.--Gear set F, parabolic type-2 relief 
Public reporting burden for this collection of information is estimated to average 1 hour per response, including the time for reviewing instructions, searching existing data sources, gathering and maintaining the data needed, and completing and reviewing the collection of information. Send comments regarding this burden estimate or any other aspect of this collection of information, including suggestions for reducing this burden, to Washington Headquarters Services, Directorate for Information Operations and Reports, 1215 Jefferson Davis Highway, Suite 1204, Arlington, VA 22202-4302, and to the Office of Management and Budget, Paperwork Reduction Project (0704-0188), Washington, DC 20503.

\begin{tabular}{|l|l|l|}
\hline 1. AGENCY USE ONLY (Leave blank) & $\begin{array}{c}\text { 2. REPORT DATE } \\
\text { June } 1995\end{array}$ & $\begin{array}{r}\text { 3. REPORT TYPE AND DATES COVERED } \\
\text { Technical Memorandum }\end{array}$
\end{tabular}

4. TITLE AND SUBTITLE

Influence of Tooth Profile Modification on Spur Gear Dynamic Tooth Strain

6. AUTHOR(S)

Fred B. Oswald and Dennis P. Townsend
5. FUNDING NUMBERS

WU-505-62-36

IL162211A47A
7. PERFORMING ORGANIZATION NAME(S) AND ADDRESS(ES)

NASA Lewis Research Center

Cleveland, Ohio 44135-3191

and

Vehicle Propulsion Directorate

U.S. Army Research Laboratory

Cleveland, Ohio 44135-3191

9. SPONSORING/MONITORING AGENCY NAME(S) AND ADDRESS(ES)

National Aeronautics and Space Administration

Washington, D.C. 20546-0001

and

U.S. Army Research Laboratory

Adelphi, Maryland 20783-1145
8. PERFORMING ORGANIZATION REPORT NUMBER

E-9691

10. SPONSORING/MONITORING AGENCY REPORT NUMBER

NASA TM-106952

ARL-TR-778

AIAA-95-3050

11. SUPPLEMENTARY NOTES

Prepared for the 31st Joint Propulsion Conference and Exhibit cosponsored by AIAA, ASME, SAE, and ASEE, San Diego, California, July 10-12, 1995. Responsible person, Fred B. Oswald, organization code 2730 , (216) 433-3957.

12a. DISTRIBUTIONAVAILABILITY STATEMENT

12b. DISTRIBUTION CODE

Unclassified - Unlimited

Subject Category 37

This publication is available from the NASA Center for Aerospace Information, (301) 621-0390.

13. ABSTRACT (Maximum 200 words)

This paper presents results of dynamic strain gage measurements performed on the NASA gear-noise rig. The experiments were part of a joint research program between NASA and the U.S. Army Research Laboratory to advance the technology of rotorcraft transmissions. Tests were performed on six sets of low contact ratio spur gears with different tooth profile modifications. Results presented include static and dynamic measurements of gear tooth strain taken over a matrix of operating conditions. The results demonstrate that a well-designed tooth profile modification can significantly reduce dynamic loads in spur gears, especially for gears which operate at high speed and under high torque. The two parabolic modifications tested were not as effective as linear modifications, possibly because the modification zone was too long.

14. SUBJECT TERMS

\begin{tabular}{|l|l|}
15. NUMBER OF PAGES \\
11
\end{tabular}

\begin{tabular}{|c|c|}
\hline $\begin{array}{c}\text { 17. SECURITY CLASSIFICATION } \\
\text { OF REPORT }\end{array}$ & $\begin{array}{c}\text { 18. SECURTY CLASSIFICATION } \\
\text { OF THIS PAGE } \\
\text { Unclassified }\end{array}$ \\
Unclassified \\
\hline
\end{tabular}

19. SECURITY CLASSIFICATION OF ABSTRACT

Unclassified 